\title{
Considering pregnancy in commercial surrogacy: a response to Bronwyn Parry
}

\author{
Luna Dolezal
}

Considering the narratives of neoliberalism that infuse and inform transnational gestational surrogacy, Bronwyn Parry's analysis is both timely and insightful. Parry demonstrates that overarching analytical frameworks employed by bioethicists to determine the potential for exploitation in transnational reproductive labour practices miss important contextual factors and the nuances of lived experience. ${ }^{1}$ Furthermore, the blanket assumptions often made by Western researchers about clinical labourers in the developing world as being financially and physically exploited under oppressive and unstable outsourced service contracts are inadequate analyses of a highly complex and varied set of social, physical, familial and medical relationships.

In order to initially unsettle the standard 'narratives of neoliberalism', in her paper Parry offers two examples of gamete donors: sperm donors for an elite Californian sperm bank and Indian gamete donors in Mumbai. Ultimately, what Parry's study demonstrates is that questions regarding the potential for economic exploitation fall on unsurprisingly gendered lines. Indian sperm donors belong to a much more advantaged social and economic class when compared with their oocyte-donating counterparts. Their motivations for engaging in sperm donation are driven by altruistic concerns regarding human welfare. In stark contrast, women in Mumbai who agree to become oocyte donors are the most disadvantaged in the city, both economically and educationally, and their motivations are of a more instrumentalist order.

While it is true, as Parry argues, that the male sperm donors, in both California and India, 'would not construct themselves, nor could they feasibly be constructed, as exploited or oppressed clinical service workers' (p. 34), it seems patently untrue that the same could be said for their female counterparts, who are driven to engage in clinical labour largely, as

Correspondence to Dr Luna Dolezal, Department of Philosophy, Durham University, 50 Old Elvet, Durham, DH1 3HN, UK; luna.dolezal@tcd.ie

Irish Research Council ELEVATE Fellow-co-funded by Marie Curie Actions.
Parry notes, 'to alleviate either permanent or temporary states of indebtedness' or as relief from occupations such as 'domestic servant or sex worker' (p. 34). Despite flagging this significant imbalance in gendered experience in her account, surprisingly Parry does not make it part of her analysis. In fact, it seems that the example of gamete donors only partially helps Parry make her point: male gamete donors may disrupt the standard narratives of neoliberalism about exploitation and alienation, however, and significantly, in the account she gives, female donors seem to reinforce and reproduce them.

Of further and central concern is the fact that the gendered differences that run deep in the case of commercial gamete donation are, of course, absolute in the case of commercial surrogacy: it is only women who can go the extra supposedly philanthropic mile and 'rent' out their wombs, providing the 'services' of gestation and birth, ultimately 'producing' the final 'product': a healthy baby. (My persistent use of scare quotes indicating the neoliberal metaphorical landscape of 'labour', private property and economic transactions through which surrogacy is routinely conceptualised.) While Parry is careful in her analysis to point out Western researchers' 'tendency to conflate many, very distinct, types of labour and labourers' (p. 34), her own account does not make much of the deep differences between, on the one hand, the experiences of male and female reproductive labourers, and, on the other hand, the stark qualitative difference, and concomitant gendered discrepancies in bodily risk, between gamete donation when compared with the embodied lived experience of gestational surrogacy.

In fact, Parry's own analysis demonstrates a broader tendency in the literature on commercial surrogacy to ignore or efface what is really at the heart of the question of surrogacy and what makes it so obviously qualitatively-and I would argue ontologically-different from other types of bodily and reproductive labour. In short, it involves pregnancy. Pregnancy is a complex lived, embodied and affective experience with a unique life-generating and kinship-generating capacity. It involves a unique relation of corporeal generosity and hospitality in which a woman uses her whole body to care for, nurture and usher a new life into being, and this is not trivial. In addition, this is a particular type of intercorporeal and affective experience that can only be realised by women and through women's bodies.

In fact, when pregnancy is mentioned in the literature about commercial surrogacy it is largely presented as a catalogue of physical and psychological symptoms through a medicalised vernacular. This glossing over of pregnancy, as a gendered, existential and phenomenological experience, in debates and discourses about commercial surrogacy is not insignificant, nor incidental. It is part of a broader tendency to efface, or render irrelevant, women's subjectivity in reproduction. From 'a time of 'expecting' a baby', as Barbara Rothman notes, pregnancy has transformed into 'a time of containing a fetus." ${ }^{2}$ This shift directly correlates to the rise of imaging technologies and the predominance of visual representations of the unborn where, since Lennert Nilsson's iconic 1966 Life Magazine feature, the disembodied fetus floats in a celestial-like black space with the maternal body (on which it is usually entirely dependent) rarely in sight. Fetal imagery presents the womb as a generalised and seemingly public space, absent of the pregnant woman's subjectivity, whose particular embodied experience would warrant ethical consideration. Of course, this logic of disembodied wombs as indifferent containers to fetuses, conceived as independent subjectivities, is central and crucial to the practice of commercial surrogacy; the terminological shift from surrogate mother to gestational carrier itself telling.

I bring up pregnancy in this short response, in part, as a means to flag the role critical medical humanities might play in debates about surrogacy and also as a suggestion for the direction Parry's own work might take in addressing the need, as she says, for 'ethnographic research that elucidates the complex lived experience of clinical labour in situ' (p. 37). Through excavating and examining the inherited, sedimented and taken-for-granted assumptions that frame or inform medical or medicalised practices-and of course the human body which is at their centre-critical medical humanities can make important interventions. In the case of commercial surrogacy, critically examining the instrumentalist metaphorical landscape and patriarchal logic which enframe women's bodies, is a crucial theoretical intervention that could 
yield a richer and more just means to negotiate how to develop the policy, practices and procedures that govern the practice.

Competing interests None.

Provenance and peer review Not commissioned; internally peer reviewed.

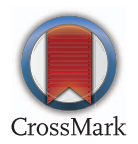

To cite Dolezal Luna. Med Humanit 2015;41:38-39.

Received 27 February 2015

Accepted 2 March 2015

\section{(S) Linked}

- http://dx.doi.org/10.1136/medhum-2014-010606

Med Humanit 2015;41:38-39.

doi:10.1136/medhum-2015-010694

\section{REFERENCES}

1 Parry B. Narratives of neoliberalism: 'clinical labour' in context. Med Humanit 2015;41:32-7.

2 Rothman BK. Laboring now: current cultural constructions of pregnancy, birth and mothering. In: Moore LJ, Kosut M, eds. The body reader: essential social and cultural readings. New York: New York University Press, 2010:50. 